\title{
EFFECTS OF MAIN ROOF FRACTURING ON ENERGY EVOLUTION DURING THE EXTRACTION OF THICK COAL SEEMS IN DEEP LONGWALL FACES
}

\author{
Jun WANG, Jianguo NING *, Lishuai JIANG *, Qingheng GU, Qiang XU and Jinquan JIANG
}

State Key Laboratory of Mining Disaster Prevention and Control, Co-founded by Shandong Province and the Ministry of Science and Technology, College of Mining and Safety Engineering, Shandong University of Science and Technology, 579 Qianwangang Road, Qingdao 266590, China

*Corresponding author's e-mail: njglxh@126.com; 1sjiang@sdust.edu.cn

\begin{tabular}{l} 
ARTICLE INFO \\
\hline Article history: \\
Received 18 April 2017 \\
Accepted 26 July 2017 \\
Available online 1 September 2017 \\
\hline
\end{tabular}

Keywords:

Deep coal mining

Microseismic monitoring

Roof fracturing

Numerical simulation

Energy evolution

\begin{abstract}
During the extraction of coal from thick seams in deep longwall faces, both high in-situ stress and a massive main roof are common. The progressive fracturing in this massive main roof leads to an increase in the front abutment stress and changes in the strain energy of the coal seam which can lead to dynamic disasters such as rockbursts. Based on the mining conditions observed in Panel 5301 of the Xinhe Coal Mine, microseismic (MS) and borehole stress monitoring, along with numerical simulations, was used to propose an evolution law for coal mine roof fracture, front abutment stress, and strain energy. Results indicate that as the roof collapses during the progress of extraction, the transmission point for overburden load moves forward such that the peak front abutment stress advances to $20-25 \mathrm{~m}$ in front of the working face. The coal mass within $22-90 \mathrm{~m}$ in front of the working face was observed to accumulate $176.2 \mathrm{~kJ}$ of strain energy, with the peak strain energy increasing from $80.15 \mathrm{~kJ}$ to $136 \mathrm{~kJ}$. The data collected and analyzed in this research provides a theoretical basis for forecasting the location of mining-induced rockburst based on observed fracturing in the main roof.
\end{abstract}

\section{INTRODUCTION}

When extracting coal from deep underground, the movement of overlying strata induced by mining activities, especially the fracturing of the main roof, results in stress redistribution (Tan et al., 2017). This stress redistribution changes the strain energy of the surrounding rock in mining-disturbed zones. If the change in the energy of the coal-rock system is severe enough, it can result in dynamic disasters (Wang et al., 2013; Lu et al., 2015; Zhu et al., 2016). It has been demonstrated that once main roof fracturing occurs, the stress concentration factor and strain energy of the loaded coal-rock increases, frequently resulting in rockbursts, particularly when the deep coal seam is very thick. Therefore, quantitatively relating the fracturing of the main roof to the change in strain energy in the rock around the longwall not only helps to predict the development of stress-induced dynamic disasters, but also helps to improve future design proposals for pre-reinforcement of the mine roadway.

In the past 50 years, in order to uncover the mechanism of different mining-induced disasters (roof fall, roadway instability, rockburst, and etc.), many researchers have studied the relationship between the movement of overlying strata and the evolution of abutment stress/strain energy in mining-disturbed zones (Kong, 2014; Jiang et al., 2016). In China, the average depth of an underground coal mine was less than $500 \mathrm{~m}$ until the $20^{\text {th }}$ century. As a result, the main tasks required in most underground coal mines were strata behavior control, roof management, and etc. (Ren et al., 2014; Wang et al., 2015). The key to addressing these issues is understood the influence of roof beam movement on the evolution of abutment stress. Many theoretical and numerical models, as well as technical methods, have been developed to analyze the change rule for the abutment stress distribution, stress concentration regions, and the relocation of the peak abutment stress as the main roof moves (Zhang et al., 2014; Ning et al., 2017).

At present, the depletion of shallow coal resources and the capabilities of new technologies have led to a remarkable increase in the depth of underground coal mines. Many coal mines are now developed more than $1000 \mathrm{~m}$ underground (Liu et al., 2016). Because of the significantly higher magnitude of stress, rockbursts occur more often in the longwall faces of the excavations, posing a very serious risk to equipment and worker safety. Many authors have noted that rockbursts are an energy phenomenon, generally associated with evolution of strain energy in mining-disturbed zones. As a result, many scholars have attempted to develop an evolution and redistribution law for strain energy in miningdisturbed zones to assess the potential danger of rockbursts. Wang et al. (2016) assessed dynamic 
changes in strain energy due to mining using the finite difference software package FLAC3D in attempt to define the relationship between the change in energy and the periodic weight. Similarly, Rezaei et al. (2015) evaluated an accumulation and dissipation law of energy on a longwall mining face.

According to the available literature, the movement of overlying strata is associated with the development of abutment stress and strain energy which can interact to establish the necessary conditions for dynamic disasters. Much of the accumulation and release of energy which accompanies mining activities is developed by the concentration and redistribution of abutment stress (Hu et al., 2017). In the case of longwall mining, which proceeds under the constantly shifting effects of overburden weight, abutment stress is continuously formed and changed by the movement of the main roof (Zhu et al., 2016). Therefore, it is necessary to understand the relationship between the movement of the main roof and the changes in the energy of the surrounding rock as longwall mining is conducted.

The present study, based on geological conditions observed in a typical longwall panel from the Xinhe Mine in the city of Jining, China, investigates the main roof separation and fracturing by using in-situ microseismic observations. The evolution of abutment stress is then quantified by borehole stress monitoring, and an analysis of the relationship between the observed stress and the movement of the main roof is conducted. Finally, an accumulation and release law of strain energy due to main roof fracturing is obtained, providing a basis for rockburst risk evaluation and improved rock support design.

\section{CASE STUDY \\ ENGINEERING BACKGROUND}

Geographically, the Xinhe Mine is located in Jining City, Shandong province, China and has a designed annual production of 90,000 tones. There are three key mineable coal seams in this mine, labelled \#3, \#16 and \#17, of which Seam \#3 was the only one being actively mined at the time of this study. Coal Seam \#3 has a mean thickness of $10.2 \mathrm{~m}$, a buried depth of $940 \mathrm{~m}$, and is nearly horizontal with an average dip angle of $6^{\circ}$, varying from 5 to $9^{\circ}$. The typical layout of the working face is shown in Figure 1a, which depicts longwall Face 5301, $844 \mathrm{~m}$ long and $100 \mathrm{~m}$ wide. Both the northeast and northwest sides of the longwall Face 5301 consist of unmined solid coal, and the southwest side abuts longwall Face 5302. Longwall Face 5301 was mined using the inclined longwall-retreating all-caving fully mechanized mining method with a mining speed of 4-5 m/d along the wall. A simplified stratigraphic column, based on core logging of this panel, is shown in Figure 1b. The roof strata of this panel was mainly composed of mudstone, fine sandstone, sandstone \& siltstone, and siltstone, etc. The immediate roof consisted of a fourrock layer (sandstone \& siltstone, fine sandstone, siltstone, and mudstone) with a mean thickness of $29.8 \mathrm{~m}$, which directly caved into the gob following the advance of the shield support. The main roof was primarily composed of fine sandstone and siltstone with a mean thickness of $41.8 \mathrm{~m}$.

The exact magnitudes of the in-situ stresses were unknown in the mine region. So that the ensuing numerical simulation would accurately reflect the insitu stress orientation and magnitude, stress measurements were conducted as part of this study. These measurements were carried out at two locations (A and B) along longwall Face 5301, as shown in Figure 1a. The stress relief method was employed to measure stresses with the results listed in Table 1. It can be seen in these measurement results that the major horizontal stress (28.41 MPa-28.66 MPa) was higher than the vertical stress, with the ratio of $\sigma_{\mathrm{hmax}} / \sigma_{\mathrm{v}}$ varying from 1.15-1.19.

Table 1 In-situ stress measurement results.

\begin{tabular}{lcccc}
\hline Station & $\begin{array}{c}\sigma_{\mathrm{hmax}} \\
(\mathrm{MPa})\end{array}$ & $\begin{array}{c}\sigma_{\mathrm{hmin}} \\
(\mathrm{MPa})\end{array}$ & $\begin{array}{c}\sigma_{\mathrm{v}} \\
(\mathrm{MPa})\end{array}$ & $\sigma_{\mathrm{h} \max } / \sigma_{\mathrm{v}}$ \\
\hline $\mathrm{A}$ & 28.41 & 23.18 & 24.72 & 1.15 \\
$\mathrm{~B}$ & 28.66 & 24.53 & 24.91 & 1.19 \\
Mean & 28.54 & 23.86 & 24.82 & 1.17 \\
\hline
\end{tabular}

\section{FIELD MONITORING SCHEME}

To conduct an in-depth investigation of mininginduced strata movement, stress change behaviors at longwall Face 5301 were measured by three different field monitoring programs, described as follows:

1. For the field monitoring of overburden movement, a 16-channel ARAMIS M/E MS system developed by the Poland Institute of Innovative Techniques was used. The ARAMIS MS system consists of a real-time monitoring recorder server, an analyzer, accelerometers, and a seismic data transmission system. The monitoring frequency range of a typical sensor used was $0-150 \mathrm{~Hz}$, a sampling rate of $500 \mathrm{~Hz}$, a response range of $100 \mathrm{~m}$, and a minimum positioning energy of $100 \mathrm{~J}$. To determine the spatial location of seismic sources, the constant velocity model $\left(V_{\mathrm{P}}=4000 \mathrm{~m} / \mathrm{s}\right.$ for geophones $\# 1-6, \quad V_{\mathrm{P}}=3000 \mathrm{~m} / \mathrm{s}$ for geophones \#7-10, and $V_{\mathrm{P}}=2800 \mathrm{~m} / \mathrm{s}$ for geophone \#16) was used. The sensor readings were converted into a digital signal by digital transmission system which then transmitted the data to a real-time monitoring recorder server using optical fiber cables.

The horizontal and vertical location errors of the MS sensors were significantly reduced by optimizing their arrangement with consideration of the spatial characteristics of rock mass fracture and the convenience of sensor installation. A total of nine geophones, numbered \#1-9 in Figure 1a, were installed underground in the mine: $\# 1-8$ were installed in longwall Face 5301, while \#9 was located in a bedrock borehole to satisfy the D-value optimization criteria ( $\mathrm{Li}$ et al., 2017). The geophones were attached to rebar bolts 


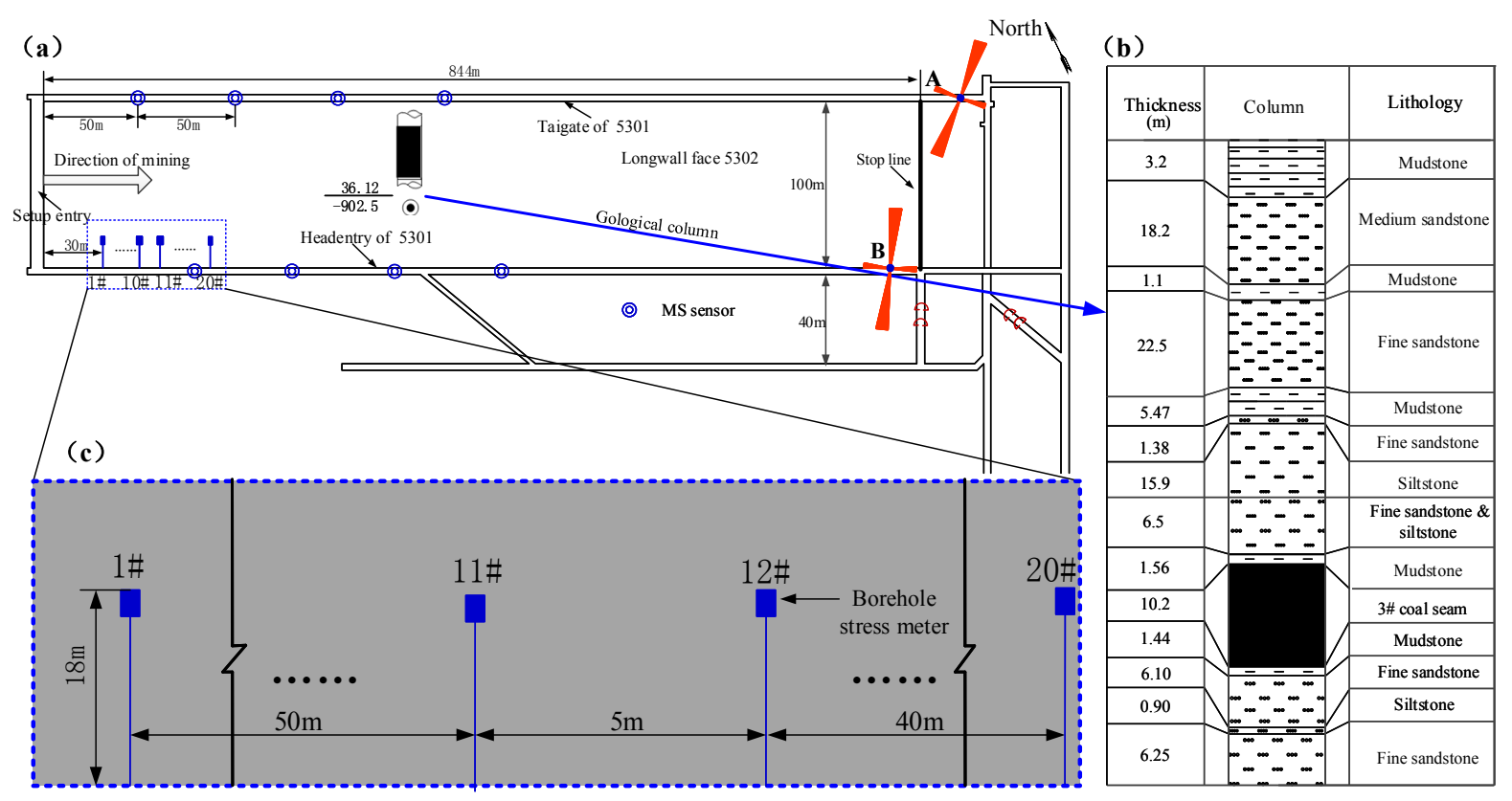

Fig. 1 Plan view of local panel layout; (b) Typical geological column; (c) Monitoring stations for front abutment stress.

Table 2 Locating results of the blasting events.

\begin{tabular}{|c|c|c|c|c|}
\hline $\begin{array}{c}\text { Blast } \\
\text { Number }\end{array}$ & location & Blasting location (m) & Event location (m) & Error (m) \\
\hline \multirow{3}{*}{1} & $\mathrm{x}$ & 3918680.521 & 3918678 & \multirow{3}{*}{7.3} \\
\hline & $\mathrm{y}$ & 39451447.423 & 39451454 & \\
\hline & $\mathrm{z}$ & -954.056 & -956 & \\
\hline \multirow{3}{*}{2} & $\mathrm{x}$ & 3918681.435 & 3918683 & \multirow{3}{*}{10.2} \\
\hline & $\mathrm{y}$ & 39451448.126 & 39451458 & \\
\hline & $\mathrm{z}$ & -955.032 & -953 & \\
\hline \multirow{3}{*}{3} & $\mathrm{x}$ & 3918679.211 & 3918682 & \multirow{3}{*}{6.4} \\
\hline & $\mathrm{y}$ & 39451446.769 & 39451453 & \\
\hline & $\mathrm{z}$ & -956.159 & -958 & \\
\hline
\end{tabular}

installed in the intact roof structures of the gateroads using tight screw thread connections, which allowed staff to remove a sensor from a readily fracturing zone. With the advancement of the working face, the geophone nearest the advancing face was relocated to the next unused sensor location. Before using the monitoring system to detect MS events, the system needed to be calibrated for the particular working conditions in the mine. To calibrate the sensors for this research, we conducted a program of site blasting at known locations. The calibration experiments indicated that the sensor results were close to the known locations, indicating that the source location accuracy satisfied the necessary engineering requirements (Table 2).

2. To monitor the redistribution of abutment stress, twenty borehole stress meters, located $18 \mathrm{~m}$ into the coal seam, were set up at the tailgate (Fig. 1c). The interval between adjacent monitoring stations was set at $5 \mathrm{~m}$ along the axial direction of the longwall, and the first monitoring station was placed $50 \mathrm{~m}$ from the working face setup entry. To protect the stress meters, once the coal face was less than $5 \mathrm{~m}$ from a meter, the meter was removed, and a new station was installed following the station furthest from the advancing working face.

3. To monitor shield leg support pressures in realtime, a KJ216 support pressure monitoring system, produced by UROICAC. LTD., was operated. The monitoring range of the pressure sensor was 0-60 MPa.

\section{MOVEMENT EVOLUTION OF OVERBURDEN WITH MINING}

Using the temporal-spatial distribution of MS events, the fracturing morphology of the overburden strata accompanying mining activities on longwall Face 5301 can be identified. Figure 2 shows the vertical distribution of MS events from 28 November, 2015 to 5 January, 2016 (over which period the working face advanced $175.3 \mathrm{~m}$ from setup entry). It should be noted that in Figure 2, the interval between adjacent horizontal lines is $20 \mathrm{~m}$, and the main roof is located in the area between the two red lines.

As shown in Figure 2, MS events were occurred in the \#3 coal seam, as well as in its floor and roof, 


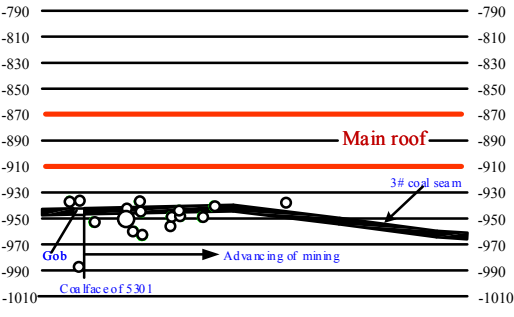

(a) Nov. 28, 2015- Nov. 30, 2015

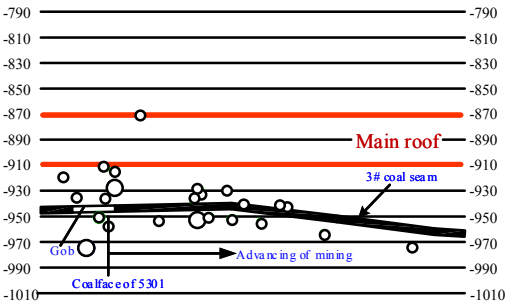

(d) Dec. 7, 2015- Dec. 10, 2015

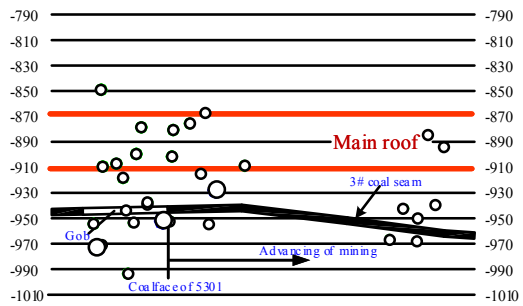

(g) Dec. 16, 2015- December 17, 2015

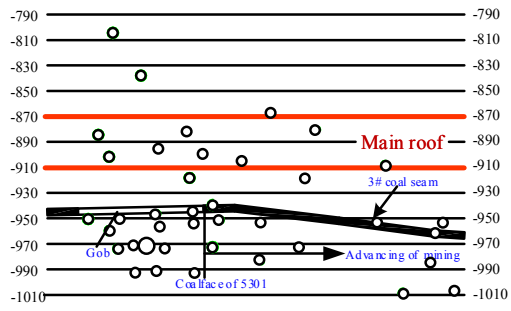

(j) Dec. 24, 2015- December 25, 2015

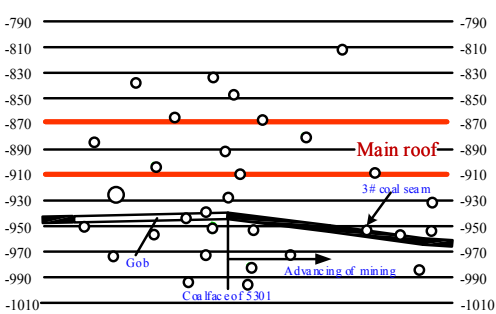

(m) Dec. 31, 2015- Jan. 2, 2016

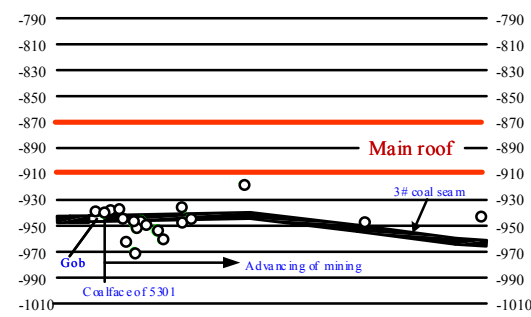

(b) Nov. 1, 2015- Nov. 3, 2015

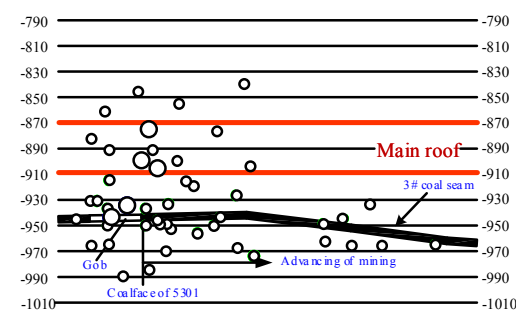

(e) Dec. 11, 2015- Dec. 12, 2015

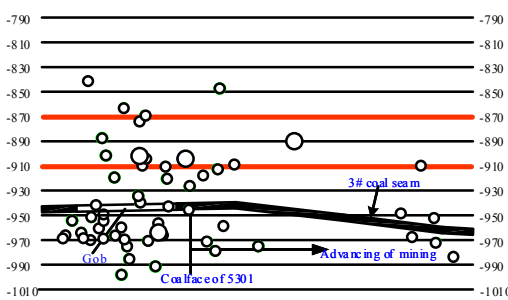

(h) Dec. 18, 2015- Dec.19, 2015

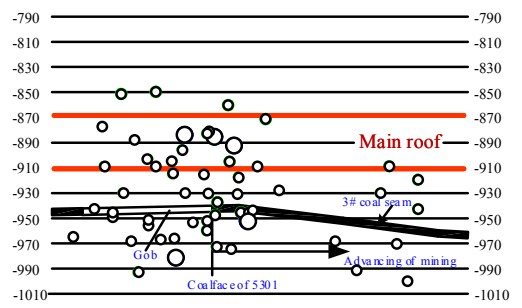

(k) Dec. 26, 2015- December 27, 2015

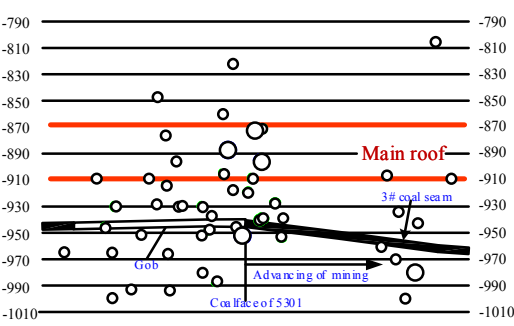

(n) Jan. 3, 2016- Jan. 4, 2016

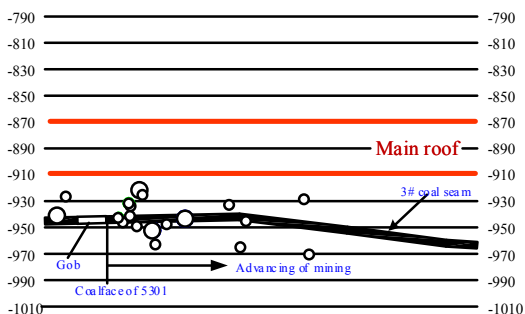

(c) Nov. 4, 2015- Nov. 6, 2015

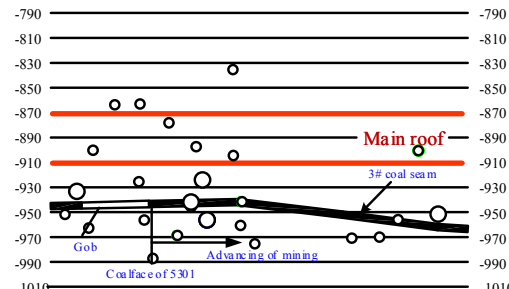

(f) Dec. 13, 2015- Dec. 15, 2015

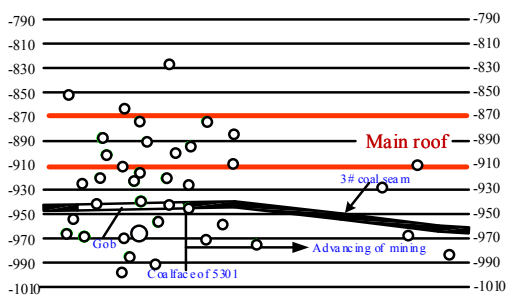

(i) Dec. 20, 2015- Dec. 21, 2015

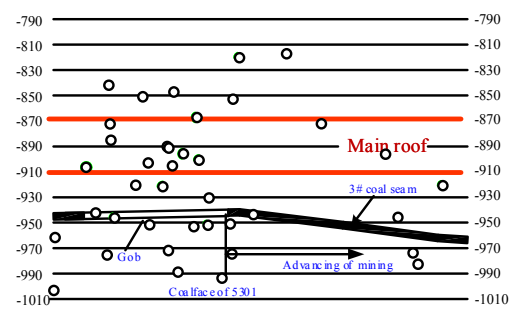

(1) Dec. 28, 2015- Dec. 30, 2015

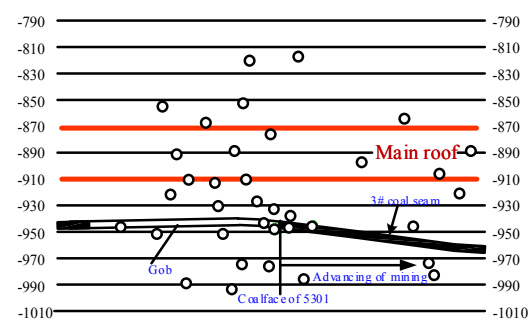

(p) Jan. 5, 2016- Jan. 7, 2016

Fig. 2 Temporal-spatial distribution of MS events. (small circle: $0-3 \times 10^{3} \mathrm{~J}$; big circle: $>3 \times 10^{3} \mathrm{~J}$ ).

owing to the deformation and failure of the roof-coalfloor structure induced by mining activity on longwall Face 5301. It also can be seen that the MS activity in surrounding rock has obvious spatial and temporal characteristics and which develop with the advance of mining along the longwall face. It can be deduced that these MS events were mainly impacted by the working face mining. From 28 November to 20 December 2015, the working face advanced $37.25 \mathrm{~m}$ from setup entry, in Figures 2a-d. As shown in Figures $2 \mathrm{a}-\mathrm{d}$, the MS events were relatively sparse around the coal seam, floor, and immediate roof of longwall 5301, indicating that little failure or largescale caving activity did occurred at this time. From 11 December to 12 December, 2015 (Fig. 2e), the daily MS events and energy releases began to rise. Some MS events were located in roof. Interestingly, a considerable portion of the high-energy MS events were located inside the main roof. Especially on 11 December, 2015 (by which time the working face had advanced $40.25 \mathrm{~m}$ ), the maximum energy of a single MS event located inside the main roof was greater than $1 \times 10^{4} \mathrm{~J}$, implying that the main roof was likely first fractured in a broken step of $40.25 \mathrm{~m}$. It also can 


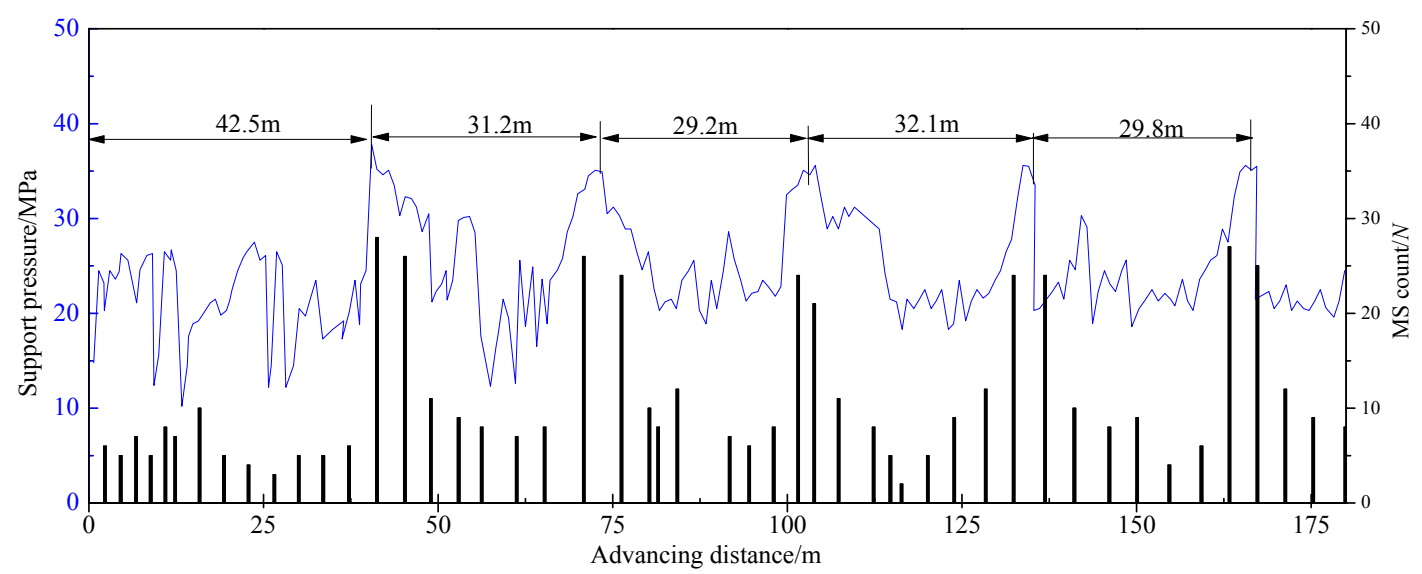

Fig. 3 Typical support pressure curve.

Table 3 High-energy MS events inside the main roof location, energy release.

\begin{tabular}{lllcc}
\hline Date & $L(\mathrm{~m})$ & $L_{0}(\mathrm{~m})$ & \multicolumn{2}{c}{ MS event inside main roof } \\
\cline { 4 - 5 } & & & $E(\mathrm{~J})$ & $X(\mathrm{~m})$ \\
\hline December 11, 2015 & 40.25 & 40.25 & 12641 & 16.3 \\
December 18, 2015 & 70.85 & 29.6 & 4962 & 16.2 \\
December 26, 2015 & 101.55 & 30.7 & 4301 & 15.6 \\
January 1, 2016 & 132.4 & 30.85 & 4652 & 15.3 \\
January 11, 2016 & 163.3 & 30.9 & 4896 & 16.2 \\
\hline
\end{tabular}

Note: $L$ represents the advancing distance of longwall face 5301; $X$ represents horizontal spacing between the coalface of 5301 and the high-energy MS event location; $E$ represents the high-energy MS event energy release; $L_{0}$ represents the broken step of the main roof.

be deduced that the main roof was fractured following the large-scale structural instability. From 13 December to 17 December, 2015, the MS events and energy releases decreased, with most MS events scattered in the surrounding rock beneath the main roof (Figs. 2e-f). The maximum energy of individual MS events was smaller than $3 \times 10^{3} \mathrm{~J}$, which indicates that large scale failure, did not occur. However, in Figure $2 \mathrm{~h}$, covering the time between 18 December to 19 December, 2015, high-energy MS events again began to increase, with three notable high-energy events in the main roof on 18 December, 2015 (by which time the working face had advanced $69.85 \mathrm{~m}$ ). Most low-energy MS events were located behind the working face 5301, mainly in the roof and floor. Additionally, the maximum energy of a single MS event exceeded $8 \times 10^{3} \mathrm{~J}$, indicating that the main roof had fractured in a broken step of $29.6 \mathrm{~m}$ (69.85 $40.25=29.6 \mathrm{~m})$. As show in Figures 2i-p, as the longwall face advanced, MS events and energy releases fluctuated periodically. Interestingly, when the incidence of MS events and energy releases began to increase, high-energy MS events were mainly concentrated in the main roof. For example, in Figures $2 \mathrm{k}$ and $2 \mathrm{n}$, by which time the longwall face had advanced $100.55 \mathrm{~m}$, and $131.4 \mathrm{~m}$, respectively, larger energy sources were mainly concentrated in the main roof, indicating that the corresponding broken steps of the main roof were $30.7 \mathrm{~m}(100.55-69.85=$
$30.7 \mathrm{~m})$ and $30.85 \mathrm{~m}(131.4-100.55=30.85 \mathrm{~m})$, respectively.

In past investigations, it has been found that the support pressure is violently affected when the main roof is fractured. The length of the fractured main roof is referred to as the weighting step. In order to estimate the weighting step, support pressures were monitored with typical results as shown in Figure 3. It can be observed that the first weighting step was around $42 \mathrm{~m}$ and the periodic weighting steps was about $30 \mathrm{~m}$. Note that the energy release sharply increases at weighting time, with energy releases relatively stable at other times. Therefore, by using the temporal-spatial distribution of high-energy MS events located inside main roof, the fracturing morphology of the main roof of longwall Face 5301 during mining activities can be identified.

The horizontal distances between the highenergy MS events inside the main roof and the coal face are listed in Table 3. It can be seen that as the working face advanced to a distance of $175.3 \mathrm{~m}$, the horizontal distance from fracture event to coal face varied from $15.3-16.3 \mathrm{~m}$, or about $15 \mathrm{~m}$ on average.

\section{ABUTMENT STRESS EVOLUTION WITH THE FRACTURING OF THE MAIN ROOF}

In conjunction with average behavioral observations, monitoring results can be used to determine the evolution of abutment stress induced by 

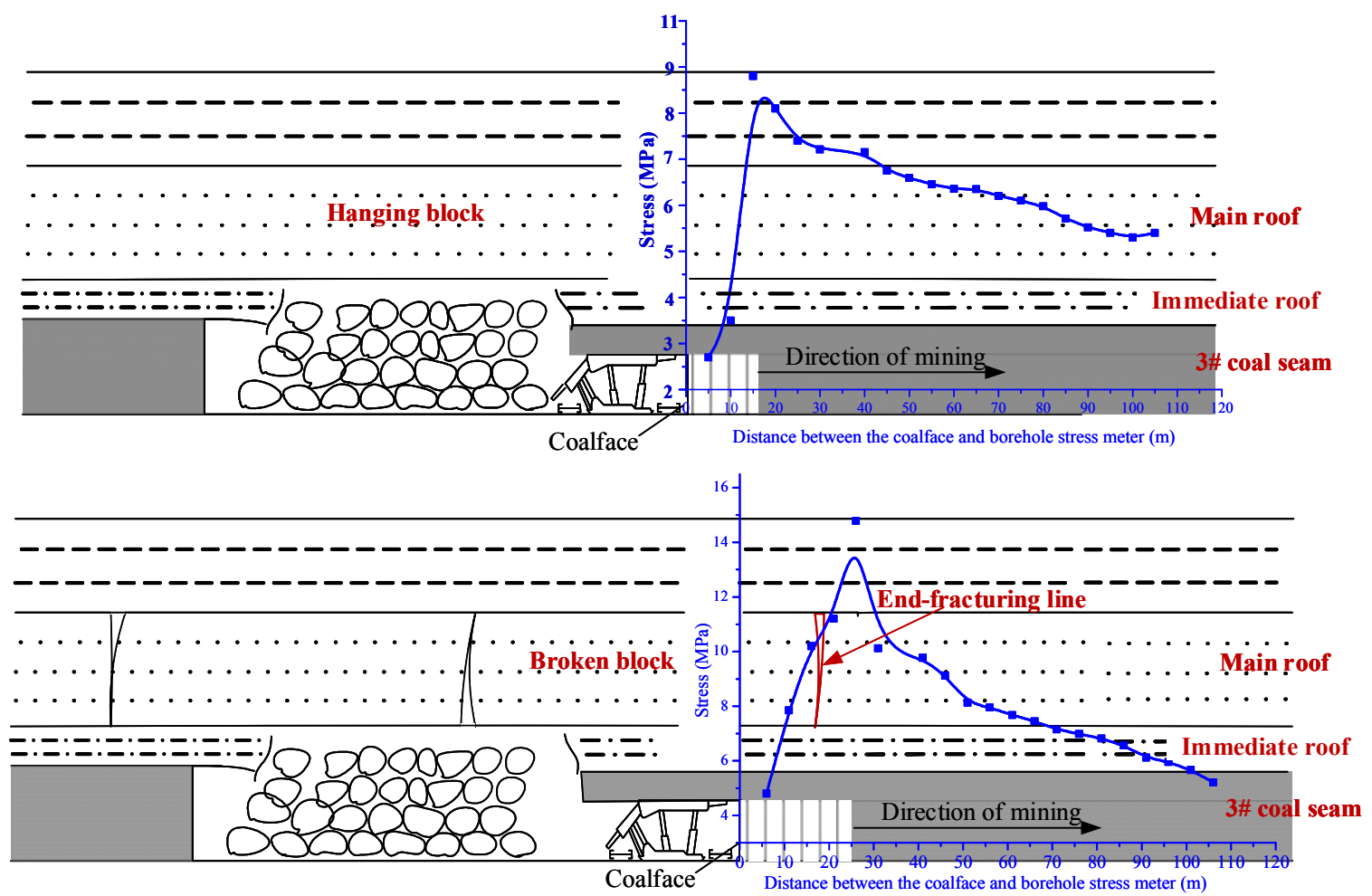

(a)

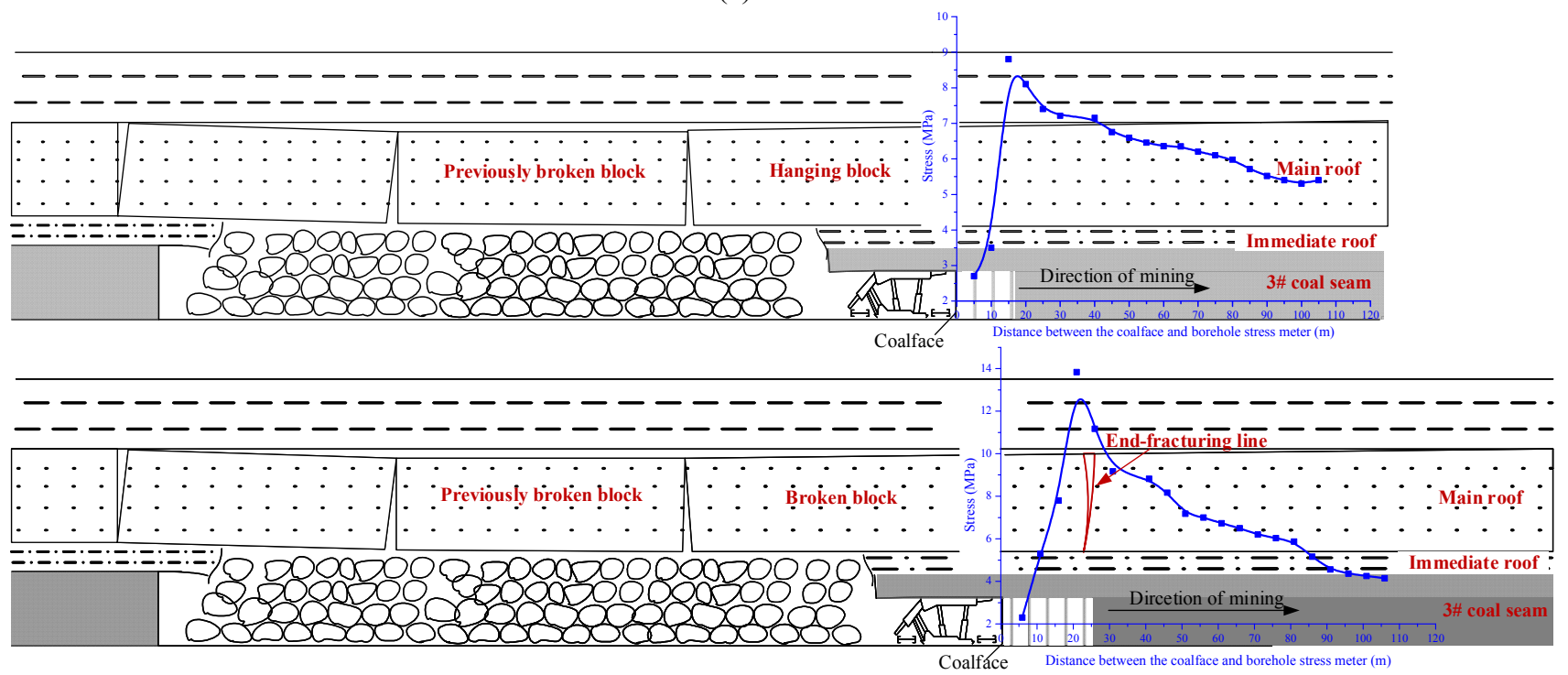

(b)

Fig. 4 Front abutment distribution obtained from in-situ monitor. (a) Front abutment distribution, 10 December to 11 December, 2015; (b) Front abutment distribution, 17 December to 18 December, 2015.

the fracturing of the main roof. Figures $4 \mathrm{a}$ and $4 \mathrm{~b}$ present the monitoring results obtained from 10 December to 11 December, 2015, and from 17 December to 18 December, 2015, respectively. The blue line in these figures represents the change in abutment stress. In order to better understand how the evolution of abutment stress is affected by the fracturing of the main roof, we will also describe the structural failure models of the main roof of longwall Face 5301, as deduced from the MS monitoring results.
Figure 4 shows the stress distribution in the abutment of longwall Face 5301 as the working face approached. It can be seen that on 10 December, 2015 (Fig. 4a, when the working face had advanced $37.25 \mathrm{~m}$ from the setup room), the largest stress increase of $3.96 \mathrm{MPa}$ was measured at a distance of $15.8 \mathrm{~m}$ in front of the working face, indicating the location of the peak front abutment stress. With the further advance of the working face to $40.25 \mathrm{~m}$ (on 11 December, 2015), the largest stress increase of 9.8 MPa was measured at a distance of $26.6 \mathrm{~m}$ in front 
Table 4 Rock strata properties used in the numerical model.

\begin{tabular}{lcccccc}
\hline Lithology & Density $\left(\mathrm{kg} / \mathrm{m}^{3}\right)$ & $K(\mathrm{GPa})$ & $G(\mathrm{GPa})$ & $C(\mathrm{MPa})$ & $\sigma_{\mathrm{t}}(\mathrm{MPa})$ & $\phi\left(^{\circ}\right)$ \\
\hline Medium sandstone & 2500 & 9.3 & 6.8 & 1.9 & 0.98 & 31 \\
Mudstone & 1700 & 5.7 & 4.1 & 0.4 & 0.01 & 14 \\
Fine sandstone & 2650 & 11.6 & 8.5 & 3.2 & 1.2 & 33 \\
3\# coal seam & 1900 & 2.15 & 1.29 & 2.2 & 1.6 & 38 \\
Siltstone & 2600 & 13.6 & 9.7 & 2.1 & 0.7 & 30 \\
Mudstone \& fine sandstone & 2500 & 8.3 & 6.6 & 1.8 & 0.7 & 35 \\
\hline
\end{tabular}

Note: $K$ is bulk modulus, $G$ is shear modulus, $C$ is cohesion, $\phi$ is friction angle

Table 5 Cap pressures' in the numerical gob model.

\begin{tabular}{llllllllllll}
\hline Strain $(\mathrm{mm} / \mathrm{mm})$ & 0 & 0.025 & 0.05 & 0.075 & 0.1 & 0.125 & 0.15 & 0.175 & 0.2 & 0.225 & 0.25 \\
\hline Stress $(\mathrm{MPa})$ & 0 & 0.1 & 0.8 & 1.3 & 2.1 & 3.1 & 4.6 & 6.8 & 10.2 & 18.5 & 32.2 \\
\hline
\end{tabular}

Table 6 Material parameters for gob model.

\begin{tabular}{lccccc}
\hline Parameter & Density $\left(\mathrm{kg} / \mathrm{m}^{3}\right)$ & $K(\mathrm{GPa})$ & $G(\mathrm{GPa})$ & $\phi\left(^{\circ}\right)$ & Dilation $\left(^{\circ}\right)$ \\
\hline Value & 1000 & 7.69 & 6.21 & 21 & 6 \\
\hline
\end{tabular}

of the working face. From 10 December to 11 December, 2015, the working face advanced $3 \mathrm{~m}$ but the peak front abutment stress shifted $10.8 \mathrm{~m}$. On 11 December, 2015, once the main roof was fractured (based on the MS monitoring results, the horizontal distance from main roof beam end-fracturing to coal face was $16.3 \mathrm{~m}$ ), the broken main roof sagged downward. As a result, the coal mass located beneath the broken main roof could be confirmed to have failed, resulting in the redistribution of stress, again advancing the location of peak front abutment stress.

To investigate the reproducibility of the monitoring results, the data obtained between 17 December and 18 December, 2015, shown in Figure $4 \mathrm{~b}$, was also analyzed. It can be seen from this figure that on 18 December, 2015, the main roof was fractured at a distance of $16.2 \mathrm{~m}$ in front of the working face, causing the location of peak front abutment stress to advance from $14.5 \mathrm{~m}$ to $25.6 \mathrm{~m}$ in front of the working face. This data illustrates and confirms that as the working face of the longwall advances, the peak front abutment stress also gradually advances in the direction of working face progress. However, when the main roof beam fractures, the stress in the surrounding rock is redistributed, further shifting the location of peak front abutment stress.

\section{ENERGY EVOLUTION IN FRONT OF WORKING FACE INDUCED BY MAIN ROOF FRACTURING}

In this section, longwall Face 5301 is numerically modelled to improve the understanding of the energy change law resulting from the fracturing of the main roof.

\section{MODEL DESCRIPTION}

The model was built according to the geological conditions of longwall Face 5301 in the Xinhe coal mine. The length, width, and height of the model was $300 \mathrm{~m}, 210 \mathrm{~m}$, and $160 \mathrm{~m}$, respectively. The model was consisted of 387,300 elements. Considering that the top of the modelled region was located about $900 \mathrm{~m}$ below the ground surface, a compressive stress of $22.5 \mathrm{MPa}$ was loaded to the top of the model to replicate the overburden. Horizontal restraints were applied in the $\mathrm{X}$ - and $\mathrm{Y}$-directions of the model, while downward vertical restraint was applied in the Zdirection. Initial stresses were applied accordance with the in-situ stress test results, with the horizontalto-vertical stress ratio set to 1.17 in both the $\mathrm{X}$ - and $\mathrm{Y}$ directions. Considering the scale effect, the rock mass properties used in the numerical simulation were as listed in Table 4.

The strain-softening model, based on the Flac3D Mohr-Coulomb failure model with nonassociated shear and associated tension flow rules, was chosen as the failure criterion for the coal seam and its overburden strata (Maleki, 2017; Zhao et al., 2017). In accordance with practice observed in the literature, the residual-to-peak cohesion ratio used in the strainsoftening model was 1/10 (Jiang et al., 2016 and 2017). Based on previous experience simulating coal seams and surrounding strata, a plastic shear strain threshold of $0.3 \%$ was established.

According to the results of the MS field monitoring of overburden movement, the first broken step of the main roof occurred at $40.25 \mathrm{~m}$, followed by periodic broken steps of, on average, $30.5 \mathrm{~m}$. For modelling convenience, the first and periodic broken steps were assumed at $40 \mathrm{~m}$ and $30 \mathrm{~m}$, respectively, and the horizontal distance from the main roof beam end-fracture to the coal face was assumed to be $16 \mathrm{~m}$. To simulate the caving of the immediate roof, the double-yield model was used with the calibrated input parameters shown in Tables 5 and 6 (Esterhuizen et al., 2010; Mahdi et al., 2012; Lawson et al., 2017). 


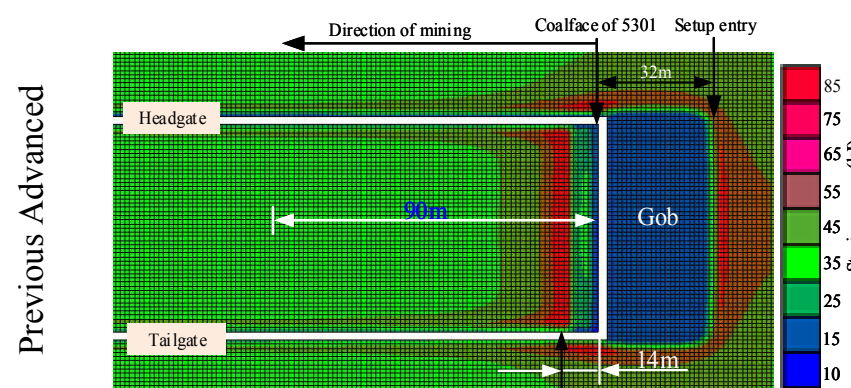

Peak strain energy
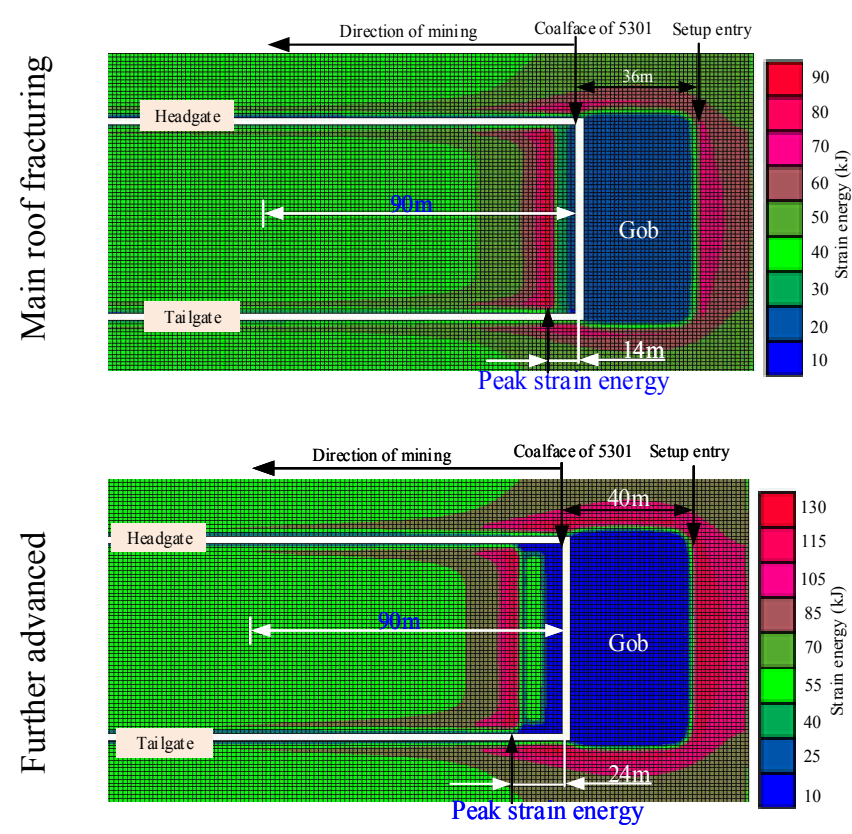

(a) Frist fracturing

Fig. 5 Distribution of strain energy in coal seam.

During the advancement of the longwall working face, a very soft elastic material was used to simulate the broken main roof. The Young's modulus of this material was set at $190 \mathrm{MPa}$, and the Poisson's ratio was set to 0.3 (Jiang et al., 2012; Cheng et al., 2010).

\section{ENERGY REDISTRIBUTION IN FRONT OF THE LONGWALL WORKING FACE}

The strain energy stored in the rock mass at a large buried depth is:

$E_{i j}=\frac{1}{2} \sigma_{i j} \varepsilon_{i j}$

when combined with the generalized form of Hooke's law, the strain energy of a coal mass after the longwall working face is advanced is:

$U=\frac{1}{2 E}\left[\sigma_{1}^{2}+\sigma_{2}^{2}-2 \mu\left(\sigma_{1} \sigma_{2}+\sigma_{2} \sigma_{3}+\sigma_{1} \sigma_{3}\right)\right]$

When implemented with FISH, the strain energy density can be obtained using Eq. (2). Figure 5 illustrates the energy redistribution in front of the coal working face during the first and periodic roof
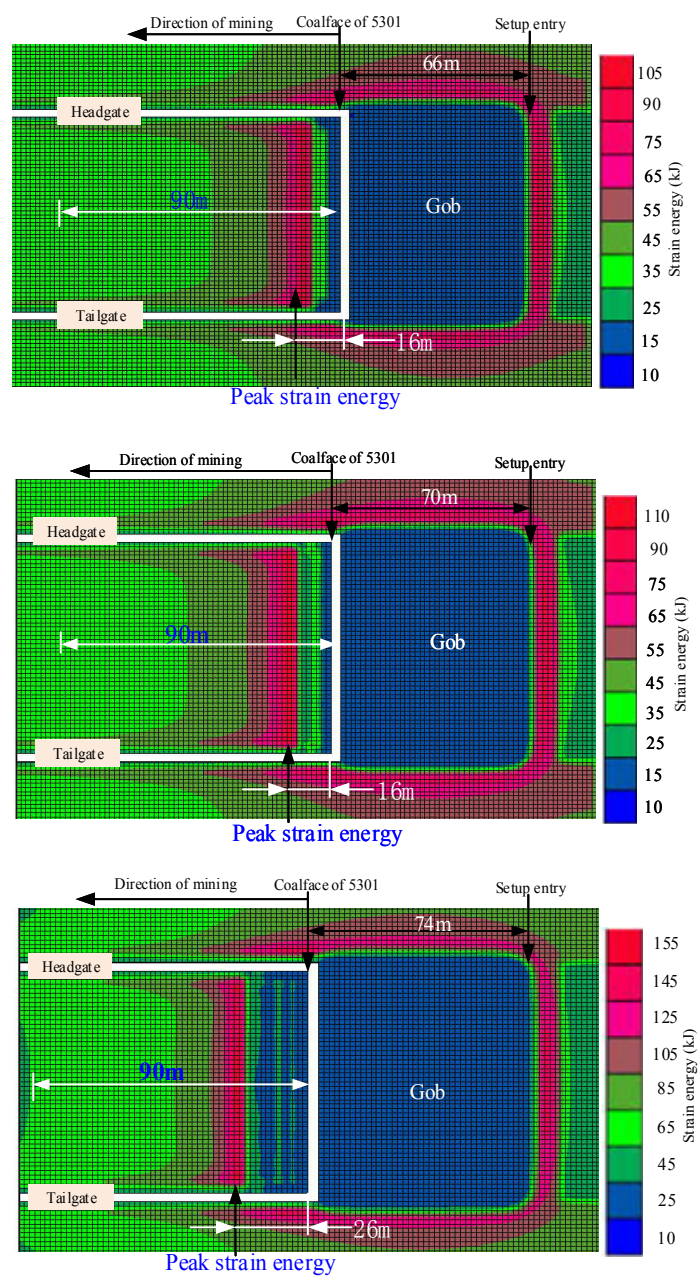

(b) Frist periodic fracturing weighting steps. Note that the plastic failure coal element in front of the working face is referred to as the energy release zone (ERZ), owing to the energy released in events occurring here.

Figure 5 shows that as the working face advances, the immediate roof caves directly into the gob. However, main roof remains hanging in a large area though it is thoroughly fractured, resulting in strain energy accumulation and release, as well as stress redistribution. In other words, when the longwall working face further advances, the peak strain energy also gradually advances and the ERZ is extended.

Taking the first periodic weighting step as an example, it should be noted that due to the main roof fracturing, the coal element in front of the working face fails as a result of the strain energy accumulation and release. As shown in Figure 5, once the working face had advanced $66 \mathrm{~m}$ from the setup entry, the strain energy reached a peak value (about $110 \mathrm{~kJ}$ ) at a distance of $18 \mathrm{~m}$ in front of the working face. The region of plastic failure induced by the panel extraction was also located approximately $18 \mathrm{~m}$ in front of the working face, making the ERZ in the 


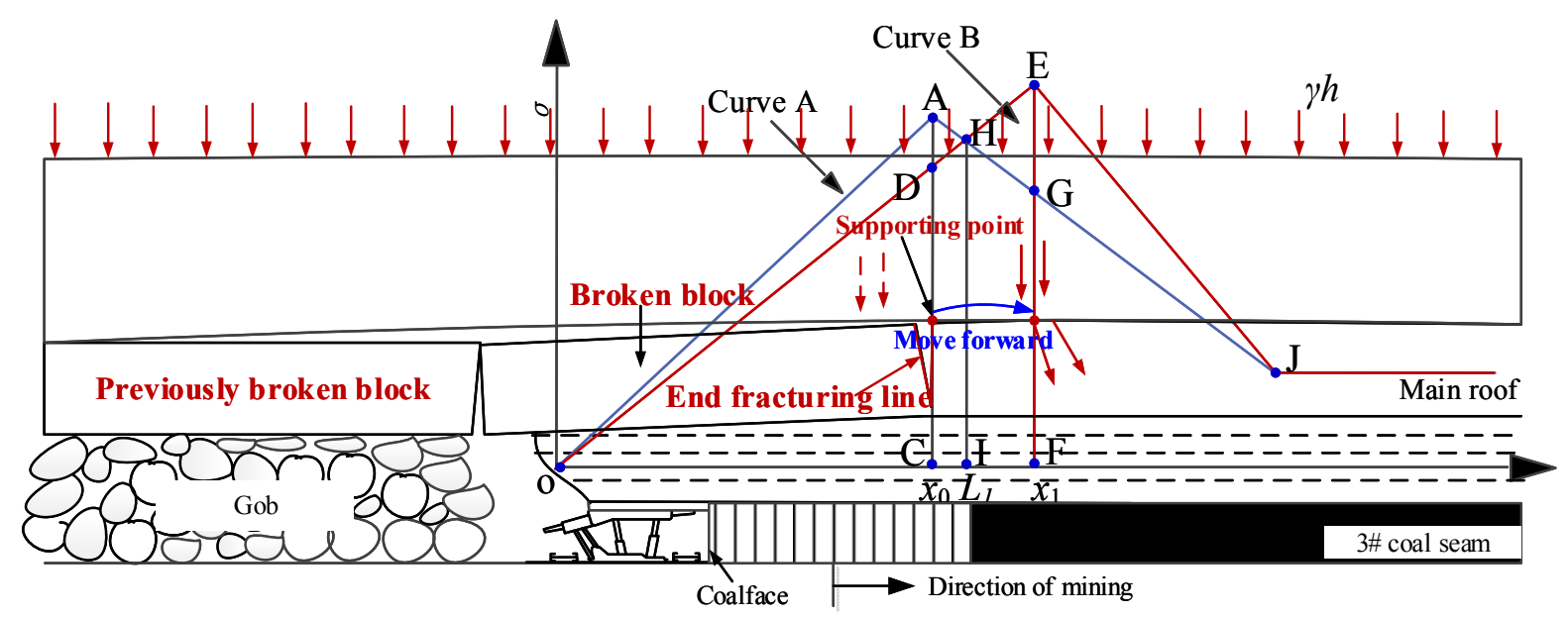

Fig. 6 Relationship between the front abutment stress and main roof fracturing.

longwall panel located within $0-18 \mathrm{~m}$ of the working face, while in coal further than 18-90 $\mathrm{m}$ from the working face, the strain energy in the coal seam decreased slowly with distance to a steady value (about $36.2 \mathrm{~kJ}$ ) owing to the low degree of disturbance of the longwall face. However, as the working face advanced to $70 \mathrm{~m}$, the main roof again reached its span limit and fracturing occurred, as also demonstrated by MS monitoring (the horizontal distance from main roof beam end-fracturing to working face was about $16 \mathrm{~m}$ ). Meanwhile, the energy stored inside the main roof was released in a short time interval, and some of this energy was converted into kinetic impact energy which propagated into the coal seam in the form of elastic waves. As a result, the coal mass around the broken main roof failed, accompanied by strain energy changes. Generally, the peak strain energy released in roof fractures was up to three times that of the unfractured main roof, and the width of the ERZ was enlarged to $26 \mathrm{~m}$. Further than 26-90 m away from the working face, strain energy from roof fractures was also larger than that of the unfractured main roof by about $145.6 \mathrm{~kJ}$.

\section{THE RELATIONSHIP BETWEEN ENERGY EVOLUTION AND MAIN ROOF FRACTURING}

The immediate roof collapses directly into the caved zone, so the immediate roof does not exist in the gob. However, past field observations have indicated that the main roof may continue to hang in the form of a voussoir beam and only collapse into the caved zone after the working face has been advanced further. Field MS monitoring indicated that in the Xinhe coal mine, the main roof was periodically fractured at a step of about $30 \mathrm{~m}$. Using to these findings, the relationship between the energy evolution of the rock and the fracturing of the main roof can be further understood.

As shown in Figure 6, immediately prior to main roof fracturing, the hanging block that is going to break begins to sag downward. The overburden load (including the main roof and upper layer loads) is transmitted into the coal seam through a supporting point (the contact point between the hanging block and the upper layer). As a result, the front abutment stress (Curve $A$ in Figure 6) forms in the coal seam under the influence of the overburden load, with a value of $\sigma_{\mathrm{A}}$, and a horizontal distance of $x_{0}$ in front of the coal face. As the working face is further advanced, the limit span of the hanging block is reached and fracturing occurs. Owing to the large bulking factor of the immediate roof, after a small rotation, the broken block of the main roof remains connected to the previously broken block, developing a voussoir beam structure. The separation between the broken block and upper layers is increased, causing the supporting point to further advance with lower coal mass failure accompanying energy release. As a result, the stress originating from the overburden load also moves forward, and front abutment stress redistribution occurs. In other words, the peak front abutment stress moves forward from $x_{0}$ to $x_{1}$ on Curve $\mathrm{B}$ in Figure 6. As this occurs, the hanging area of the upper layer is gradually enlarged, and the stress concentration factor at the clamped edges increases, potentially resulting in the increase in accumulated energy. Thus, main roof fracturing can be understood to serve two functions in mining-induced energy evolution: the driving of coal mass energy release, and the increase in accumulated energy.

Energy evolution results from the evolution of the front abutment stress. Therefore, we can calculate the released and accumulated energy according to the distribution of front abutment stress. For simplicity, assuming that front abutment stress is a linear distribution, these energies can be expressed by Eqs. (3) and (4). Immediately prior to main roof fracturing, the strain energy $W_{1}$ stored in the coal mass within a horizontal distance $L_{1}$ in front of working face is described by the trapezoidal area $S_{\mathrm{OAHI}}$. After main roof fracturing, the coal mass within this ERZ is failed, and residual strain energy $W_{2}$ that stored in ERZ was triangle area of $S_{\mathrm{ODHI}}$. Therefore, the released energy $W_{3}$ is the difference in the stored 
strain energy and the residual strain energy, $S_{\mathrm{OAHI}^{-}}$ $S_{\text {ODHI }}$. Additionally, because the peak front abutment stress moves forward from $x_{0}$ to $x_{1}$, the accumulated strain energy $W_{4}$ beyond $L_{1}$ from the coalface is given by the triangular area $S_{\mathrm{EHJ}}$.

$$
\begin{aligned}
& \sigma_{1}=\left\{\begin{array}{lr}
a x, & 0 \leq \mathrm{x} \leq \mathrm{x}_{1} ; \\
-c d+d, & x_{1}<x<x_{2} ; \\
e & x_{2}<x_{1} ;
\end{array}\right. \\
& \sigma_{2}=\left\{\begin{array}{lr}
m x, & 0 \leq \mathrm{x} \leq \mathrm{x}_{1}^{\prime} ; \\
-k x+l, & x_{1}^{\prime}<x<x_{2}^{\prime} ; \\
e & x_{2}^{\prime}<x_{1} ;
\end{array}\right.
\end{aligned}
$$

Where, $a, c, d, e, m, k$, and $l$ are constants obtained from an experiment

As discussed above, the released energy $W_{3}$ and the accumulated strain energy $W_{4}$ can be obtained by:

$$
\begin{aligned}
& W_{3}=S_{O A H I}-S_{O D H I}=\int_{0}^{L_{1}} \sigma_{1} d x-\int_{0}^{L_{1}} \sigma_{2} d x \\
& W_{4}=S_{H I K J E}-S_{H I K J}=\int_{L_{1}}^{L_{J}} \sigma_{2} d x-\int_{L_{1}}^{L_{J}} \sigma_{1} d x
\end{aligned}
$$

According to on-site measurements, the parameters $a, c, d, e, m, k$, and $l$ are 2.93, 0.24, 47.57, $80,1.84,0.32$, and 53.94, respectively. From the field investigation and numerical simulation, the parameters $L_{1}, L_{2}, \sigma_{\mathrm{A}}, \sigma_{\mathrm{B}}, \sigma_{\mathrm{J}}, x_{1}, x_{2}, x_{1}^{\prime}$, and $x_{2}^{\prime}$, are $22.9 \mathrm{~m}, 80 \mathrm{~m}, 44 \mathrm{MPa}, 46 \mathrm{MPa}, 28.54 \mathrm{MPa}, 15 \mathrm{~m}$, $80 \mathrm{~m}, 25 \mathrm{~m}$ and $80 \mathrm{~m}$, respectively. With the integration of Eqs. (5) and (6), the released energy $W_{3}$ and the accumulated strain energy $W_{4}$ are $188.05 \mathrm{~kJ}$, $125.58 \mathrm{~kJ}$, respectively, demonstrating that the theoretical results are similar to those determined using numerical modelling.

\section{CONCLUSIONS}

In order to understand the energy evolution induced by the fracturing of the main roof of longwall coal mines, in-situ investigations and numerical modelling of longwall Face 5301 of the Xinhe coal mine were conducted. The results of these investigations presented in this paper can be summarized in follows:

1. With the advancement of longwall Face 5301, the main roof periodically fractured, as indicated by periodic MS event counts located inside the main roof. MS monitoring results suggest that the periodic broken step of the main roof was about $30 \mathrm{~m}$, and the end-fracturing line was typically about $15 \mathrm{~m}$ in front of the working face.

2. According to in-situ monitoring of stress change and numerical modelling, when the main roof fractures, the coal mass around the end-fracturing line fails as a result of the rotation of the broken block. Meanwhile, the previously stored strain energy is released. With the increasing separation between the broken block and adjacent upper layers, the supporting point for overburden load transmission is driven forward, which results in the redistribution of front abutment stress.
3. During the extraction of a thick coal seam in a deep longwall face, the movement of rock (including fracturing and rotation) generated two different effects on the energy evolution: the driving of coal mass energy release near the endfracturing line, and the increase in accumulated energy in the coal mass away from the endfracturing line.

\section{ACKNOWLEDGMENTS}

This study was supported by the National Natural Science Foundation of China (Nos. 51574154, 51574155, 51474137, 51704182); Tai'shan Scholar Engineering Construction Fund of Shandong Province of China, Taishan Scholar Talent Team Support Plan for Advantaged \& Unique Discipline Areas.

\section{REFERENCES}

Cheng, Y.M., Wang, J.A., Xie, G.X. et al.: 2010, Threedimensional analysis of coal barrier pillars in tailgate area adjacent to the fully mechanized top caving mining face. International Journal of Rock Mechanics and Mining Sciences, 47, 8, 1372-1383.

DOI: $10.1016 /$ j.jirmms.2010.08.008

Esterhuizen, E., Mark, C. and Murphy, M.M.: 2010, Numerical model calibration for simulating coal pillars, gob and overburden response. Proceeding of the 29th International conference on Ground Control in Mining, Morgantown, WV, 46-57.

Kong, L.H.: 2014, Relationship between microseismic events and abutment pressure distribution in coal mining. Journal of Mining and Safety Engineering, 4, 525-531.

DOI: $10.13545 /$ j.issn1673-3363.2014.04.005

Hu, S.C., Tan, Y.L., Ning, J.G. et al.: 2017, Multi-parameter monitoring and prevention of fault-slip rock burst. Shock and Vibration, 4, 1-8. DOI: $10.1155 / 2017 / 7580109$

Jiang, Y.D., Wang, H.W., Xue, S. et al.: 2012, Assessment and mitigation of coal bump risk during extraction of an island longwall panel. International Journal of Coal Geology, 95, 1, 20-33. DOI: 10.1016/j.coal.2012.02.003

Jiang, F.X., Liu, Y., Zhang, Y.C. et al.: 2016, A three-zone structure loading model of overlying strata and its application on rockburst prevention. Chinese Journal of Rock Mechanics and Engineering, 35, 12, 23982408, (in Chinese).

DOI: $10.13722 /$ j.cnki.jrme.2016.0255

Jiang, L.S., Sainoki, A. and Mitri, H.S.: 2016, Influence of fracture-induced weakening on coal mine gateroad stability. International Journal of Rock Mechanics and Mining Sciences, 88, 307-317.

DOI: $10.1016 / j . j$ jrmms.2016.04.017

Jiang, L.S., Zhang, P.P., Chen, L.J. et al.: 2017, Numerical approach for goaf-side entry layout and yield pillar design in fractured ground conditions. Rock Mechanics and Rock Engineering, 1-23. DOI: $10.1007 / \mathrm{s} 00603-017-1277-0$

Lu, C.P., Liu Y., Wang H.Y. et al.: 2016, Microseismic signals of double-layer hard and thick igneous strata separation and fracturing. International Journal of Coal Geology, 160-161, 28-41. DOI: 10.1016/j.coal.2016.04.011 
Liu, X.S., Ning, J.G., Tan, Y.L. et al.: 2016, Damage constitutive model for rocks under cyclic loading based on energy dissipation. International Journal of Rock Mechanics and Mining Sciences, 85, 27-32. DOI: $10.1016 /$ j.ijrmms.2016.03.003

Lawson, H.E., Tesarik, D., Larson, M.K. et al.; 2017, Effects of overburden characteristics on dynamic failure in underground coal mining. International Journal of Mining Science and Technology, 27, 121129. DOI: $10.1016 /$ j.jimst.2016.10.001

Li, N., Wang, E.Y., Li, B.L. et al.: 2017, Research on the influence law and mechanisms of sensors network layouts for the source location, Journal of China University of Mining and Technology, 46, 229-236, (in Chinese). DOI:10.13247/j.cnki.jcumt.000640

Mahdi, S. and Li, C.C.: 2012, Numerical modelling of longwall mining and stability analysis of the gates in a coal mine. International Journal of Rock Mechanics and Mining Sciences, 51, 24-34.

DOI: $10.1016 /$ j.ijrmms.2012.02.002

Maleki, H.: 2017, Coal pillar mechanics of violent failure in US Mines. International Journal of Mining Science and Technology, 27, 387-392. DOI: 10.1016/j.ijmst.2017.03.001

Ning, J.G., Wang, J., Tan, Y.L. et al.: 2017, In situ investigations into mining-induced overburden failures in close multiple-seam longwall mining: A case study. Geomechanics and Engineering, 12, 4, 657-673. DOI: 10.12989/gae.2017.12.4.657

Ren, Y.F. and Ning, Y.: 2014, Changing feature of advancing abutment pressure in shallow long wall working face. Journal of China Coal Society, S1, 3842, (in Chinese). DOI: 10.13225/j.cnki.jccs.2012.1280

Rezaei, M., Hossaini, M.F. and Majdi, A.: 2015, Determination of longwall mining-induced stress using the strain energy method. Rock Mechanics and Rock Engineering, 48, 6, 2421-2433.

DOI: $10.1007 / \mathrm{s} 00603-014-0704-8$
Tan, Y.L., Liu, X.S., Ning, J.G. and Lu, Y.W.: 2017, In situ investigations on failure evolution of overlying strata induced by mining multiple coal seams. Geotechnical Testing Journal, 40, 2, 244-257. DOI: $10.1520 /$ GTJ20160090

Wang, H.W., Jiang, Y.D., Gao, R.J. et al.: 2013, Evolution of energy field instability of island longwall panel during coal bump. Rock and Soil Mechanics Journal, 34(S1), 479-485, (in Chinese).

Wang, D.C., Wang Q. and Li, S.C.: 2015, Stress distribution characteristics of deep mine in fully-mechanized sublevel caving face based on microseismic and online stress monitoring system. Journal of Mining and Safety Engineering, 32, 3, 382-388. DOI: $10.13545 /$ j.cnki.jmse.2015.03.006

Wang, J., Ning, J.G., Jiang, J.Q. et al.: 2017, Research on the energy criterion for rockbursts induced by broken hard and thick rock strata and its application. Geotechnical and Geological Engineering, 35, 731746. DOI: $10.1007 / \mathrm{s} 10706-016-0137-0$

Zhang, N., Zhang, N.C., Han, C.L. et al.: 2014, Borehole stress monitoring analysis on advanced abutment pressure induced by longwall mining. Arabian Journal of Geosciences, 7, 2, 457-463. DOI: $10.1007 / \mathrm{s} 12517-013-0831-7$

Zhu, S.T., Feng, Y., Jiang, F.X. et al.: 2016, Determination of abutment pressure in coal mines with extremely thick alluvium stratum: A typical kind of rockburst mines in China. Rock Mechanics and Rock Engineering, 49, 5, 1943-1952. DOI: 10.1007/s00603-015-0868-x

Zhao, Y.X., Jiao, Z.H. and Liu, H.B.: 2017, Simulation of ground pressure distribution at large mining height face based on GIS techniques. International Journal of Mining Science and Technology, Journal of China University of Mining and Technology, 46, 33-40. DOI: $10.13247 /$ j.cnki.jcumt.000623 